Research Article

\title{
Characterization of Air Void in Porous Asphalt Mixture Using Image Techniques and Permeability Test
}

\author{
Zhongping Tang (iD) and Fanglin Huang (iD \\ School of Civil Engineering, Central South University, 22 South Shaoshan Rd, Changsha, Hunan 410075, China \\ Correspondence should be addressed to Fanglin Huang; huangfanglin@csu.edu.cn
}

Received 6 April 2021; Accepted 3 July 2021; Published 12 July 2021

Academic Editor: José António Fonseca de Oliveira Correia

Copyright (c) 2021 Zhongping Tang and Fanglin Huang. This is an open access article distributed under the Creative Commons Attribution License, which permits unrestricted use, distribution, and reproduction in any medium, provided the original work is properly cited.

\begin{abstract}
In this study, air void contents and distributions of porous asphalt mixtures along the vertical and horizontal directions were quantitatively measured on planar images. Air void contents were determined using some image techniques; while the permeability was measured by the falling head test. Two aggregate gradations (G1 and G2) and three blow numbers (30, 40, and 50) were chosen to explore the effects of gradation and compaction effort on the porosity and permeability. Results showed that porosities and permeabilities are symmetrically distributed along the middle of the specimens; the porosities and permeabilities got the minimum values around the middle zone. A finer gradation or a significant compaction effort generally led to a lower porosity and permeability coefficient. In the horizontal direction, the air void content showed an increasing trend from the outside layer to the inner layer, indicating the nonuniformity of porosity distribution.
\end{abstract}

\section{Introduction}

Porous asphalt mixture (PAM) is featured by its large drainage capacity, which is generated by the large porosity produced by the gap-graded or open-graded aggregate structure $[1,2]$. In the US, the recommended porosity is no less than 18\%; in China, Japan, and New Zealand, the porosity should be no less than 20\% [3]. Because of its prominent air void (AV) content, PAM presents great advantages in the reduction of water splash and spray as well as risk of hydroplaning and wet skidding, leading to the improvement of the visibility in the wet weather [2]. In addition, noise reduction effectiveness is another feature that distinguishes PAM with other types of asphalt mixtures $[4,5]$. On the contrary, the interconnected porosity of PAM leads to a low-albedo value, which results in a reduction of nighttime urban heat island effect [6]. All these benefits make PAM a sustainable pavement material, which attracts extensive attentions these years.

The internal structure of PAM, including the air void characteristic and the skeleton structure, is the dominate factor affecting the durability and functionality. The permeability of PAM is mainly related with the interconnected AV content [7-9]. Generally, a linear relationship exists between the total $\mathrm{AV}$ and the interconnected $\mathrm{AV}$ content. Research from Alvarez et al. [10] showed that only very slight difference between the total $\mathrm{AV}$ content and the interconnected AV content existed. Pieralisi [11] found that no matter for falling head test or constant head test, the increase of the porosity leads to an increase of the permeability. Norhidayah et al. [12] found that PAM with coarse aggregate gradation produced larger void size with an elongated shape, producing a more obvious connectivity of the pores. Król et al. [13] found that a comparatively high permeability value was observed for porous asphalt with maximum aggregate size. Void distributions in the vertical and horizontal directions present some variabilities. Chen et al. [14] found that the length of horizontal connected voids in PAM was larger than that in the vertical direction, which resulted into a lower hydraulic conductivity in the vertical direction. Moreover, the length and curvature of horizontal pores were larger than those of vertical pores, but the diameter was smaller for horizontal pores [15]. Chen et al. [16] also have drawn the same conclusion from several 
specimens with the connected AV content ranged from $7.4 \%$ to $17.0 \%$. It is suggested to consider the effect of rainfall intensity and transverse cross slopes when measuring the permeability in pavements.

Using optical and electron microscopy, Poulikakos and Partl [17] found that a more homogeneous void structure existed in PAM with polymer-modified binder. In addition, better performing mixes had a more desirable void structure with fewer or less elongated voids and better interlocking of the aggregate. $\mathrm{Hu}$ et al. [18] employed the 3D fractal dimension (3DFD) to characterize the complexity of aggregates and found a larger 3DFD led to a more complicated and large air voids in asphalt mixture. It was reported that there existed a power function relationship between the effective air voids and the total air voids [19]. Moreover, the interconnected air voids existed when the total air void content was larger than $8 \%$. When the total porosity was larger than $15 \%$, the water inside asphalt mixture is likely to flow without water damage [20].

Besides the effects in functionality, the air void content also affects the durability of PAM [21]. Several scholars found that a coarser gradation in PAM may result in a larger content of voids in the mineral aggregate (VMA). However, a coarser gradation helps form a stronger skeleton, which leads to an improved mechanical performance [22]. For a given PAM mix, the compaction effort significantly affects the AV content. Within a certain range, the larger the compaction number, the lower the AV content and the bigger the bulk specific density of mix. Therefore, the increase of compaction efforts helps the formation of the stone-on-stone contact structure, which provides the deformation resistance. The moisture susceptibility can be used to evaluate the durability of PAM under the moisture damage effect $[2,21]$. Evaluation of moisture susceptibility based on the retained tensile strength ratio (TSR) was recommended for PAM mix design [23]. Suresha et al. [21] showed that PAM with lower AV content showed larger indirect tensile strength (ITS) and the larger tensile strength ratio (TSR). Based on macroscopic assessment, a direct relationship between the AV content and the mixture resistance to disintegration (i.e., raveling) was provided that the lower AV content led to lower abrasion loss [21]. The air void in PAM also influences the bonding condition between PAM and the underlying layer [24], which also affects the durability of PAM pavements. Another aspect about the effect of the pore structure on durability is the aging effect in PAM. Compared to dense-graded asphalts, the significant pore structure of PAMs more easily induces the aging reaction of asphalt binder [25]. Asphalt aging is accompanied by a reduction in other properties of bituminous pavements, such as antirutting, moisture damage resistance, and crack resistance [26, 27]. Hagos et al. [28] found that aging could increase the stiffness of the bitumen, which contributes the brittle failure in the contact points between the mortar and aggregates.

In characterizing the internal structure of asphalt concretes, the nondestructive techniques based on X-ray computed tomography (CT) and image analysis provided insight into the internal structure characteristics of asphalt mixture, such as the reconstruction of asphalt concrete [29, 30], AV content and distribution [7, 31-33], and damage evolution [34]. Results showed that the larger AV content existed at the top and bottom of the asphalt samples, both for Marshall and SGC samples [32, 33]. Poulikakos and Partl [17] used optical and electron microscopy to evaluate the binder type on the microstructure of porous asphalt. These techniques are generally expensive to use and require specialized personnel to operate. Relatively speaking, internal structure analysis of asphalt concretes using planar images is more straightforward and effective, especially in detecting the void content and aggregate gradation $[35,36]$.

\section{Objective and Scope}

The objective of this study is to investigate the content and distribution of air voids in PAMs with different gradations under different compaction efforts. By employing digital image processing techniques, air voids were extracted from planar images taken from cut slices. The AV in vertical direction and the uniformity of the AV distribution were both analyzed. Besides, permeability test was conducted using the falling head method. The permeability coefficients were correlated with the AV content.

\section{Materials and Mix Design}

Two type of gravel PAMs were prepared in this study with the difference in the aggregate gradation. The nominal maximum aggregate sizes of the two gradations (G1 and G2) are $12.7 \mathrm{~mm}$ and $9.5 \mathrm{~mm}$, respectively. The gradations of G1 and G2 are shown in Figure 1. It can be seen that G1 is coarser than G2. A styrene-butadiene-styrene- (SBS-) modified binder was used in this study. The asphalt content in G1 and G2 were $6.0 \%$ and $6.2 \%$, respectively. The properties of the SBS binder can be found in Table 1 .

In this study, a Superpave Gyratory Compactor (SGC) was used to compact the PAM specimens at $145^{\circ} \mathrm{C}$. Compaction was conducted at a pressure of $0.6 \mathrm{MPa}$ and an external angle of gyration of $1.25^{\circ}$. The compaction efforts were set with 30, 40, and 50 blows. Some trial tests were conducted to compact specimens with a height of $12 \mathrm{~cm}$. The porosities and permeabilities derived from the falling head test are shown in Table 2. Some preliminary conclusions can be drawn that, with the increase of the compaction effort, the porosities and permeabilities gradually decreased. With the same compaction energy, SGC specimens with G1 gradation showed larger porosities and permeabilities than specimens with G2 gradation.

\section{Laboratory Test}

4.1. Image Methodology of Air Void Detection. Slices were cut from the compacted samples with a depth of $2 \mathrm{~cm}$, which can be observed in Figure 2, in which there are 5 surfaces (No. 1 to No. 5), and were used to detect the air void content and distribution. The top and bottom surfaces were discarded due to the difficult segmentation caused by a very small range of pixels. All the tests were carried out in triplicate. 


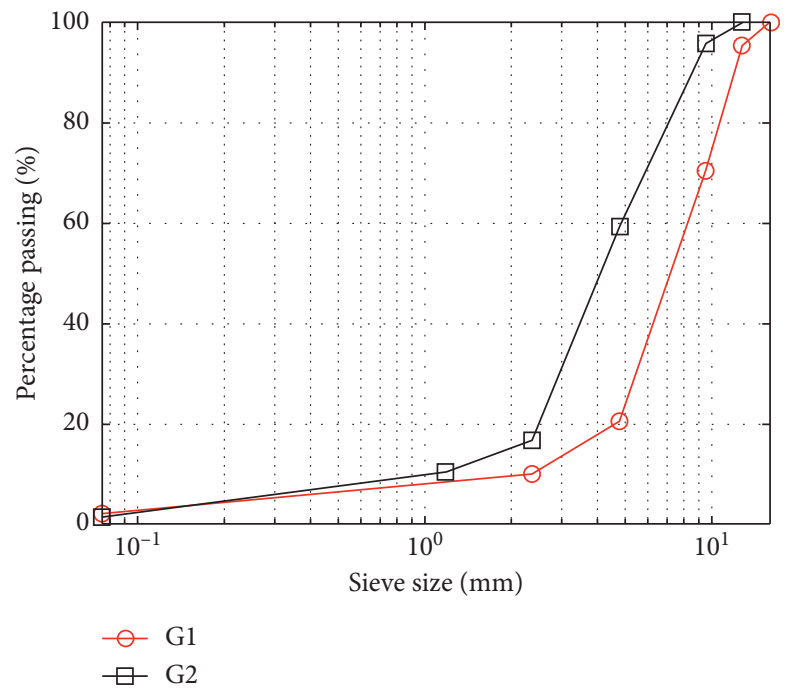

Figure 1: Aggregate gradation of OGFC.

TABle 1: Properties of SBS binder.

\begin{tabular}{lccc}
\hline Properties & Units & Requirements & Test results \\
\hline Penetration $\left(25^{\circ} \mathrm{C}\right)$ & $0.1 \mathrm{~mm}$ & $30-60$ & 54.8 \\
Ductility $\left(5^{\circ} \mathrm{C}\right)$ & $\mathrm{cm}$ & $\geq 20$ & 30.7 \\
Soft point & ${ }^{\circ} \mathrm{C}$ & $\geq 60$ & 80.7 \\
Kinematic viscosity $\left(135^{\circ} \mathrm{C}\right)$ & Pa.s & $\leq 3.0$ & 1.79 \\
Penetration index & & $\geq 0$ & 0.19 \\
\hline
\end{tabular}

Note. The requirements followed the standard (JTG E20-2011 standard test methods of bitumen and bituminous mixtures for highway engineering).

TABLe 2: Porosities and permeabilities of SGC specimens.

\begin{tabular}{|c|c|c|c|c|c|c|c|c|}
\hline \multirow{3}{*}{ Blow no. } & \multicolumn{4}{|c|}{ Porosity (\%) } & \multicolumn{4}{|c|}{ Permeability $(\mathrm{mm} / \mathrm{s})$} \\
\hline & \multicolumn{2}{|c|}{ G1 } & \multicolumn{2}{|c|}{ G2 } & \multicolumn{2}{|c|}{ G1 } & \multicolumn{2}{|c|}{ G2 } \\
\hline & Average & $\mathrm{COV}$ & Average & $\mathrm{COV}$ & Average & $\mathrm{COV}$ & Average & $\mathrm{COV}$ \\
\hline 30 & 22.8 & 0.18 & 21.1 & 0.48 & 16.57 & 0.27 & 14.99 & 0.16 \\
\hline 40 & 20.4 & 0.31 & 19.4 & 0.21 & 15.86 & 0.14 & 13.32 & 0.28 \\
\hline 50 & 18.8 & 0.09 & 17.9 & 0.14 & 14.15 & 0.37 & 12.28 & 0.22 \\
\hline
\end{tabular}

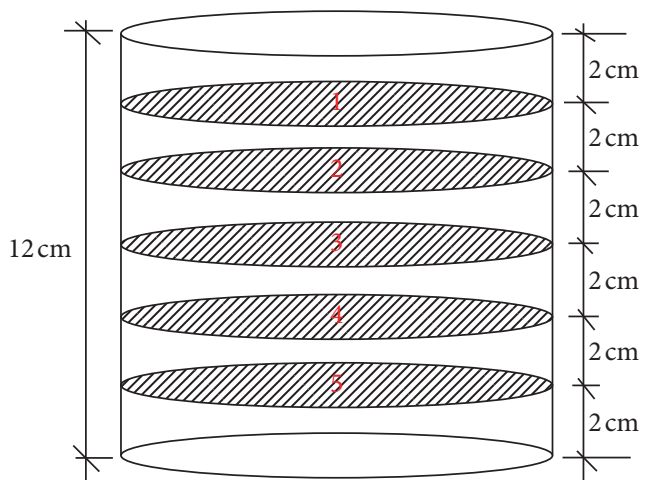

(a)

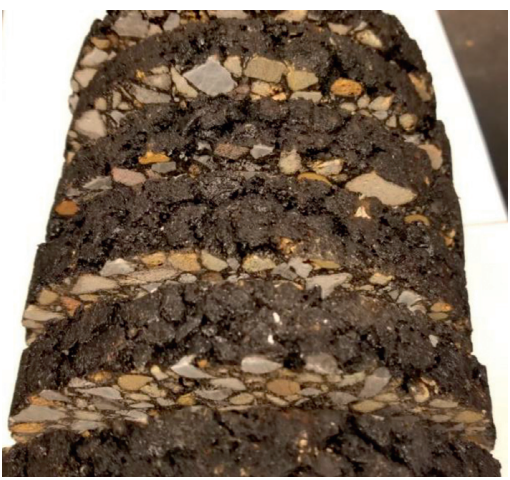

(b)

FIgURE 2: Preparation of sample slices. 


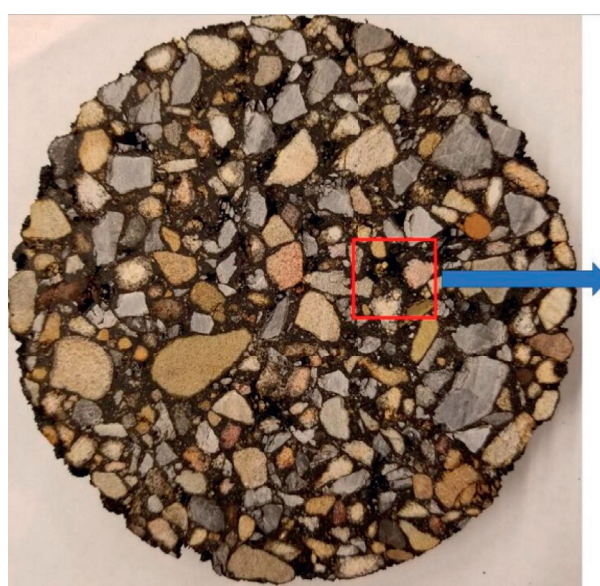

(a)

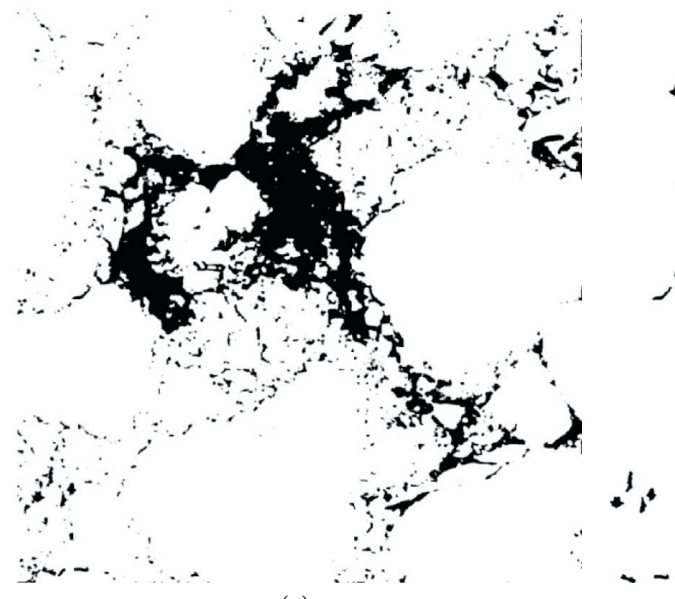

(c)

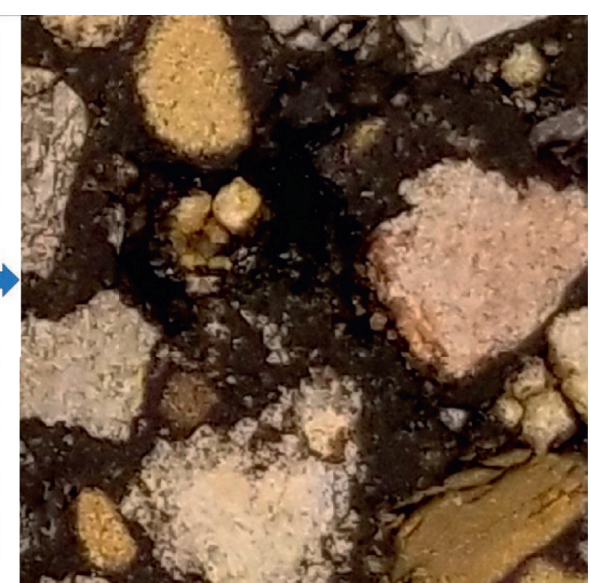

(b)

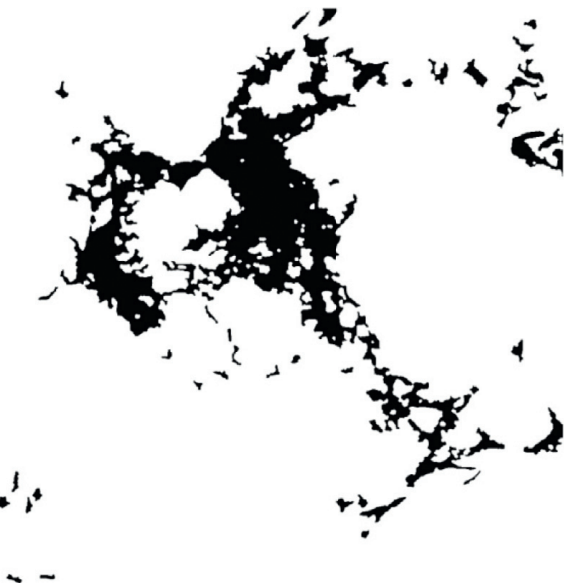

(d)

FIgURE 3: Image processing to capture air voids. (a) Sample's surface. (b) Local area extraction. (c) Image binarization. (d) Morphological open operation.

After the cutting process, slice samples would be transformed to $2 \mathrm{D}$ grayscale images. Then, binarization was conducted to segment the air voids and aggregate mastics. A binary image is a digital image which has only two possible values of each pixel: 0 and 1. In Figure 3(c), the dark part represents the air voids and the white part represents the aggregate mastics. The threshold value of the binarization operation was determined using Otsu's method [37]. In Figure 3(c), there are lots of noises after the initial binarization. The morphological opening operation was following conducted on the binary image to remove the noise. The morphological opening operation is an erosion followed by a dilation [38]. Opening is an image morphological operation that darkens small objects and entirely removes single-pixel objects such as noise spikes and small spurs [39]. Objects tend to retain their original shapes and sizes. The void ratio is determined by dividing the number of void pixels by the number of the total pixels.

In Figure 4, a plane image was divided into three parts (I, II, and III). The diameter of part I is $5 \mathrm{~cm}$. The thickness of II and III is $2.5 \mathrm{~cm}$, respectively. Apart from obtaining the air void content on the planar image, air void contents in these three layers were measured as well to quantitively characterize the uniformity of air void distribution.

4.2. Permeability Test. Permeability is an important parameter of pervious concrete since the material is designed to perform as a drainage layer in pavement structures. Falling head permeability tests were conducted to obtain the permeabilities of each slice. There are 6 slices for an SGC sample, as shown in Figure 2. Figure 5 shows the specimen and device for permeability test. To protect from the water leakage between the sample and the test device, the cylindrical specimen was wrapped with a rubber tube and tightened by circular clamps. Permeability coefficient was calculated using

$$
k=2.3 \frac{a L}{A t} \log \left(\frac{h_{1}}{h_{2}}\right),
$$

where $k$ is coefficient of permeability, $A$ is the cross-section area of the sample, $L$ is the height of a sample, in this study, and $L$ equals to $2 \mathrm{~cm}, a$ is the cross-section area of standpipe, 


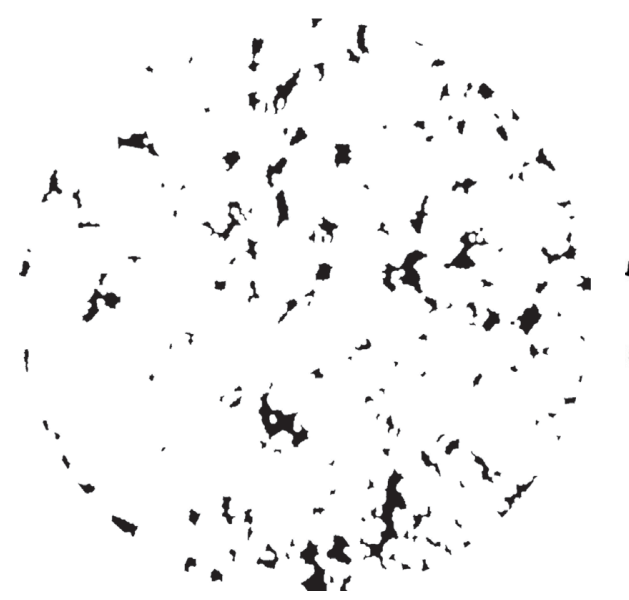

(a)

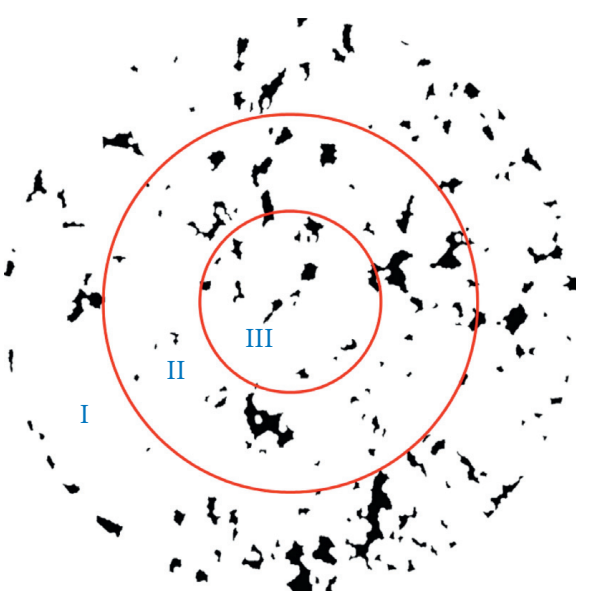

(b)

FIgURE 4: Air voids extraction in different layers. (a) Image binarization. (b) Three layers in a PAM slice.

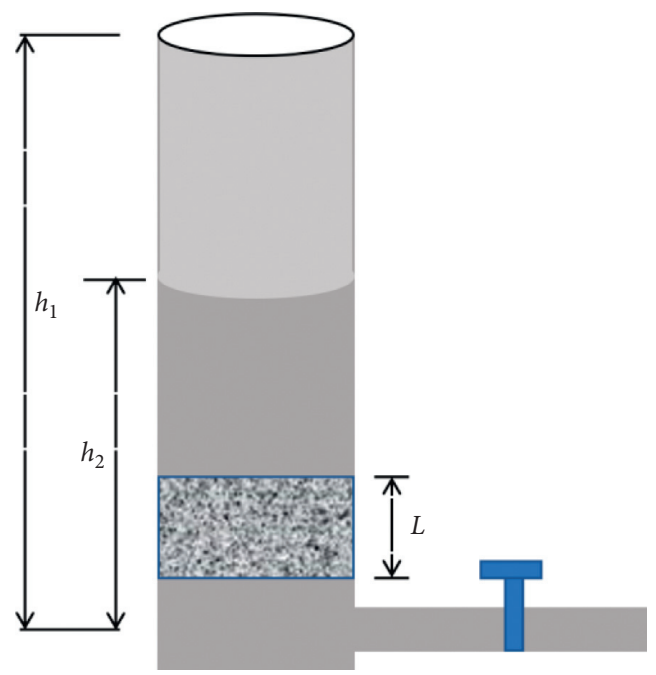

FIGURE 5: Falling head permeability test.

$t$ is the time taken for water in the standpipe to fall from $h_{1}$ to $h_{2}$, and $h_{1}$ and $h_{2}$ are the heads at the beginning and end of the measurement.

\section{Result and Discussion}

5.1. Air Void Distribution. The air voids on the two surfaces of the cylinder specimens were not measured. Therefore, porosities at 0 and $12 \mathrm{~cm}$ were not plotted in Figure 6 . In the legend, the first part represents the gradation type and the second part is the blow number. Therefore, G1-30 represents the PAM specimens with G1 gradation and the blow number is 30 . For all the specimens, as shown in Figure 6 , the porosities are symmetrically distributed along the middle of the specimens; the porosities got the minimum values around the middle zone. This conclusion generally consists of the results obtained from CT scanning [8]. This inhomogeneous AV distribution can be attributed to restriction by the top and bottom surfaces of the specimen during compaction and by a nonuniform temperature profile through the depth of the compacted mixture [40]. No matter for G1 or G2 gradation, with the increase of compaction efforts, the AV content decreased remarkably. The effect of gradation on the AV content is also clearly observed. At the same location and under the same compaction effort, PAMs with G2 gradation showed lower AV contents, indicating a finer aggregate gradation led to a denser internal structure.

Figure 7 presents the AV distributions of PAMs at different heights from the outside layer to the inside layer with the blow number of 30 . A clear trend can be observed that, from zone I to zone III, the AV content increased remarkably, indicating compaction quality in the outside layer was better. This may be ascribed to the compaction type and the constraint of the gyratory compactor. Similar with the conclusion drawn from Figure 6, AV contents at both ends of specimens $(h=2,10 \mathrm{~cm})$ were larger, while the AV content in the middle $(h=6 \mathrm{~cm})$ was lower. Comparing the 


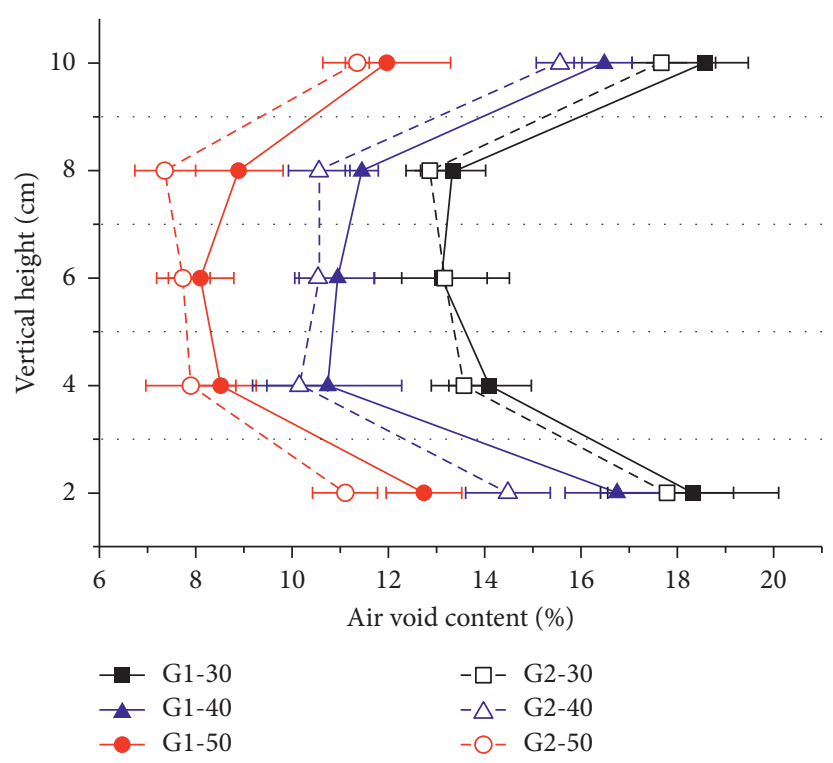

Figure 6: Air void distribution under the vertical direction.

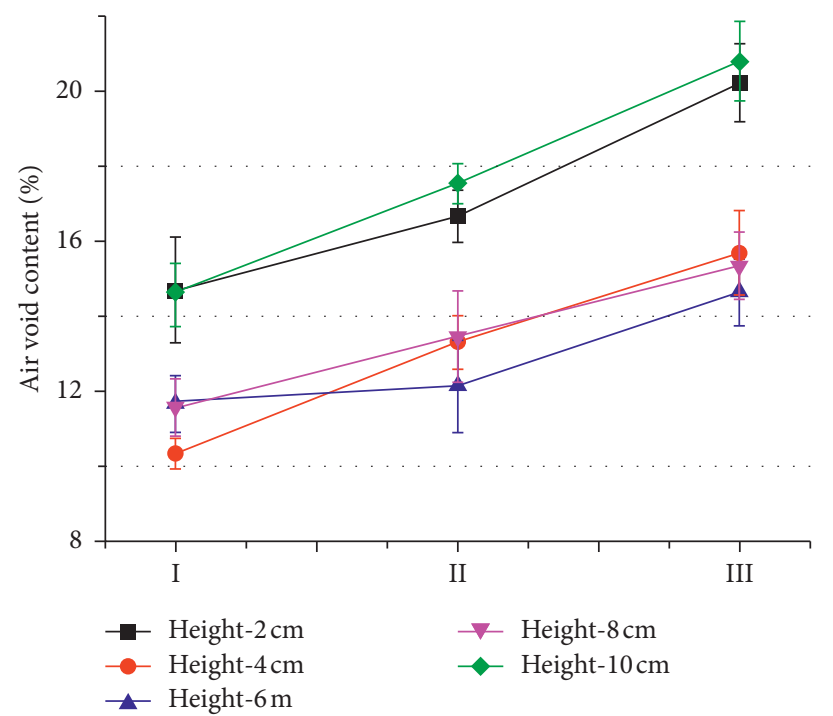

(a)

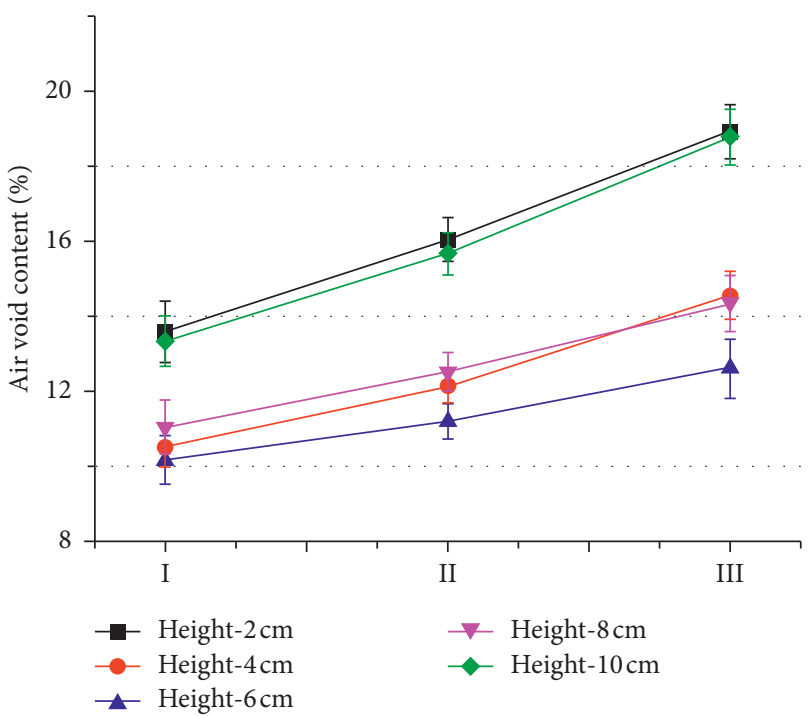

(b)

Figure 7: Air void distribution in horizontal direction. (a) G1. (b) G2.

results of PAMs with G1 and G2 gradations, specimens with G1 gradation also presented larger AV contents at the same locations.

Figure 8 presents the AV distributions of PAMs with G1 and G2 gradations from the outside layer to the inside layer. The depth of the specimens in Figure 8 is $4 \mathrm{~cm}$. From the outside layer to the inner part, AC contents increased from specimens with a same gradation and compaction number. However, the AV content of specimens with G1 gradation was generally larger than specimens with G2 gradation, indicating PAMs with G2 gradation were denser than G1.

5.2. Permeability. Permeabilities of the six slices were presented in Figure 9. The vertical points of the samples were set as $1,3,5,7,9$, and $11 \mathrm{~cm}$. Similar with the air void contents in
Figure 6, the lowest permeability coefficients were located at $5 \mathrm{~cm}$ or $7 \mathrm{~cm}$, and the largest values were at the two ends. From the two ends to the vertical middle position, permeability coefficients gradually decreased due to the decrease of porosities.

The relationship between porosity and permeability coefficient was revealed in Figure 10. It should be noted that the data of both the slices and the SGC specimens were presented. It can be obviously observed that, as the porosity increases, the permeability increases correspondingly, which agrees with other studies $[41,42]$. However, some interesting phenomenon can be observed that although the porosities of SGC specimens were larger than those of the slices, the permeabilities coefficients were lower. This is because, for a SGC specimen with a thickness of $12 \mathrm{~cm}$, tortuosity is more 


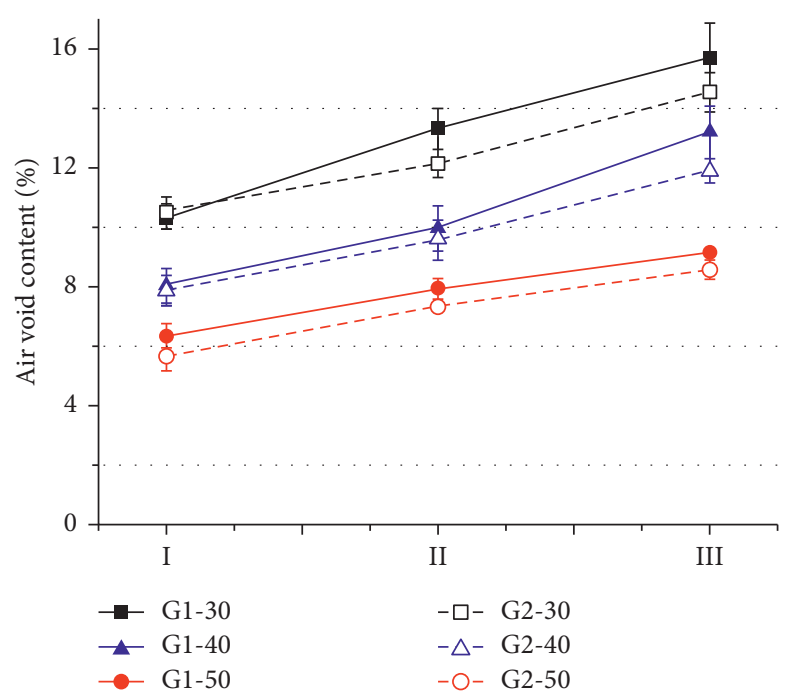

FIgURE 8: Air void distribution under different gyratory compaction numbers.

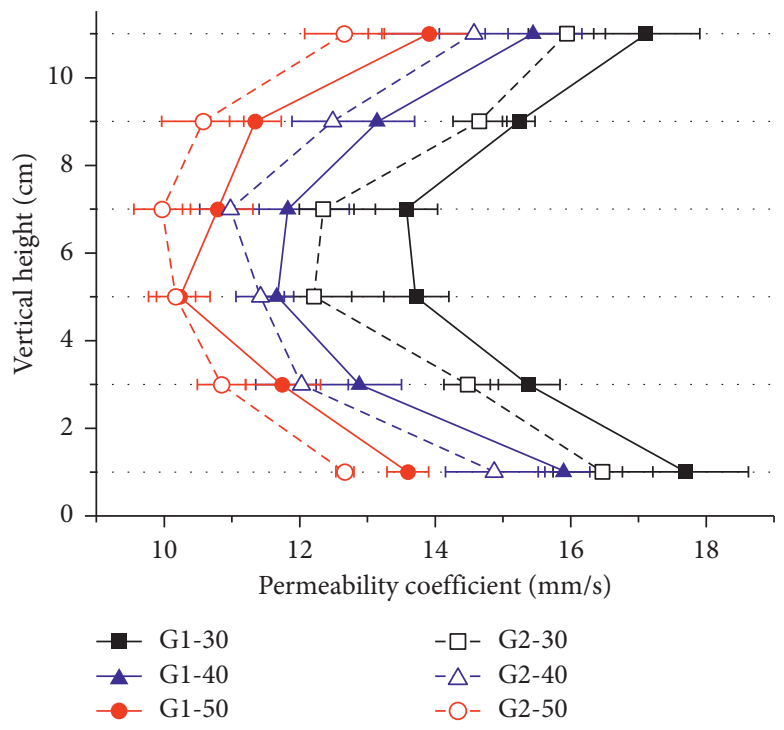

Figure 9: Result of permeability.

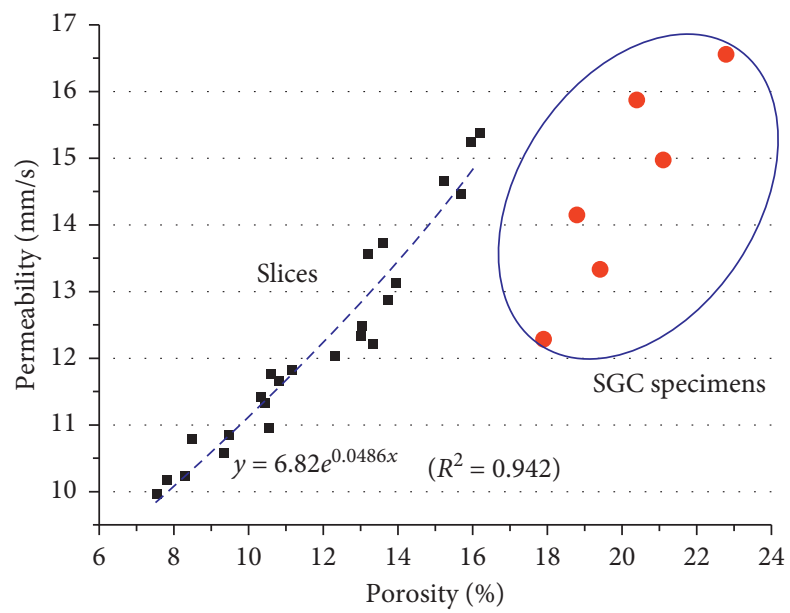

FIGURE 10: Relationship between porosity and permeability. 
significant than in the slice specimens with a lower thickness. The tortuosity definitely introduces water-flow obstructions [43], resulting in a decrease in permeability coefficient. For the slice specimens, an exponential equation was set up to represent the relationship between porosity and the permeability coefficient. However, permeability of PMA is also affected by many other factors, such as the pore structure and gradation. In this study, this equation was only for the data in this study.

\section{Conclusions}

In this study, image techniques were utilized to measure the air void contents in the vertical and horizontal directions. Falling head tests were conducted to obtain the permeability coefficients. Relationship between porosity and permeability was set. The uniformity of air void content distribution was measured by checking the porosities from the outside to the inner layer. Some conclusions can be drawn:

(1) Porosities and permeabilities are symmetrically distributed along the middle of the specimens; the porosities and permeabilities got the minimum values around the middle zone.

(2) A coarser gradation or a lower compaction effort could play the same effect in leading to a larger porosity and a higher permeability coefficient.

(3) In the horizontal direction, the air void content showed an increase trend from the outside layer to the inner layer, indicating the nonuniformity of porosity distribution.

(4) For SGC specimens with a larger thickness, tortuosity is significant, which produces a lower permeability, even though the porosities of an SGC specimen and a slice sample were the same.

(5) This study was mainly about the porosity characterization of SGC specimens. The air void distributions of field samples will be explored in the future study.

\section{Data Availability}

The data presented in this study are available from the corresponding author on request.

\section{Conflicts of Interest}

The authors claim no conflicts of interest.

\section{Acknowledgments}

This study was supported by the projects funded by the National Natural Science Foundation of China (Grant no. 51378504) and Guizhou Provincial Department of Transportation (Grant no. 2013-122-001).

\section{References}

[1] Q. Liu and D. Cao, "Research on material composition and performance of porous asphalt pavement," Journal of Materials in Civil Engineering, vol. 21, no. 4, pp. 135-140, 2009.

[2] A. E. Alvarez, A. E. Martin, and C. Estakhri, "A review of mix design and evaluation research for permeable friction course mixtures," Construction and Building Materials, vol. 25, no. 3, pp. 1159-1166, 2011.

[3] H. Wu, J. Yu, W. Song, J. Zou, Q. Song, and L. Zhou, "A critical state-of-the-art review of durability and functionality of open-graded friction course mixtures," Construction and Building Materials, vol. 237, Article ID 117759, 2020.

[4] M. Berengier, J. Hamet, and P. Bar, "Acoustical properties of porous asphalts: theoretical and environmental aspects," Transportation Research Record, vol. 1265, 1990.

[5] G. Camomilia, M. Malgarini, and S. Gervasio, "Sound absorption and winter performance of porous asphalt pavement," Transportation Research Record, vol. 1265, 1990.

[6] J. J. Stempihar, T. Pourshams-Manzouri, K. E. Kaloush, and M. C. Rodezno, "Porous asphalt pavement temperature effects for urban heat island analysis," Transportation Research Record: Journal of the Transportation Research Board, vol. 2293, no. 1, pp. 123-130, 2012.

[7] A. E. Alvarez, A. E. Martin, and C. Estakhri, "Connected air voids content in permeable friction course mixtures," Journal of Testing and Evaluation, vol. 37, no. 3, pp. 1-10, 2009.

[8] A. E. Alvarez, A. E. Martin, and C. Estakhri, "Drainability of permeable friction course mixtures," Journal of Materials in Civil Engineering, vol. 22, no. 6, pp. 556-564, 2009.

[9] Y. Zhao and X. Huang, "Design method and performance for large stone porous asphalt mixtures," Journal of Wuhan University of Technology-Materials Science Edition, vol. 25, no. 5, pp. 871-876, 2010.

[10] A. E. Alvarez, A. E. Martin, and C. Estakhri, "Internal structure of compacted permeable friction course mixtures," Construction and Building Materials, vol. 24, no. 6, pp. 1027-1035, 2010.

[11] R. Pieralisi, Characterization and Modelling of Previous Concrete, Universitat Politècnica de Catalunya, Barcelona, Spain, 2016.

[12] A. H. Norhidayah, M. Z. H. Mahmud, and P. J. Ramadhansyah, "Air void characterisation in porous asphalt using X-ray computed tomography," Advanced Materials Research, vol. 911, pp. 443-448, 2014.

[13] J. B. Król, R. Khan, and A. C. Collop, "The study of the effect of internal structure on permeability of porous asphalt," Road Materials and Pavement Design, vol. 19, no. 4, pp. 935-951, 2018.

[14] J. Chen, X. Yin, H. Wang, X. Ma, Y. Ding, and G. Liao, "Directional distribution of three-dimensional connected voids in porous asphalt mixture and flow simulation of permeability anisotropy," International Journal of Pavement Engineering, vol. 21, no. 12, pp. 1550-1562, 2020.

[15] J. Chen, J. Wang, H. Wang, P. Xie, and L. Guo, "Analysis of pore characteristics and flow pattern of open-graded asphalt mixture in different directions," Journal of Materials in Civil Engineering, vol. 32, no. 9, Article ID 04020256, 2020.

[16] S. Chen, Z. You, S.-L. Yang, A. Garcia, and L. Rose, "Influence of air void structures on the coefficient of permeability of asphalt mixtures," Powder Technology, vol. 377, pp. 1-9, 2021. 
[17] L. D. Poulikakos and M. N. Partl, "Investigation of porous asphalt microstructure using optical and electron microscopy," Journal of Microscopy, vol. 240, no. 2, pp. 145-154, 2010.

[18] J. Hu, P. Liu, D. Wang, and M. Oeser, "Influence of aggregates' spatial characteristics on air-voids in asphalt mixture," Road Materials and Pavement Design, vol. 19, no. 4, pp. 837-855, 2018.

[19] E. Masad, B. Birgisson, A. Al-Omari, and A. Cooley, "Analytical derivation of permeability and numerical simulation of fluid flow in hot-mix asphalt," Journal of Materials in Civil Engineering, vol. 16, no. 5, pp. 487-496, 2004.

[20] M. Shang, Research of Volume Parameters in Skeleton Asphalt, Southeast University, Nanjing, China, 2016.

[21] S. N. Suresha, G. Varghese, and A. U. R. Shankar, "Characterization of porous friction course mixes for different marshall compaction efforts," Construction and Building Materials, vol. 23, no. 8, pp. 2887-2893, 2009.

[22] X. Wang, X. Gu, J. Jiang, and H. Deng, "Experimental analysis of skeleton strength of porous asphalt mixtures," Construction and Building Materials, vol. 171, pp. 13-21, 2018.

[23] P. S. Kandhal and N. A. P. Association, Design, Construction, and Maintenance of Open-Graded Asphalt Friction Courses, National Asphalt Pavement Association, Greenbelt, MD, USA, 2002.

[24] W. Song, X. Shu, B. Huang, and M. Woods, "Influence of interface characteristics on the shear performance between open-graded friction course and underlying layer," Journal of Materials in Civil Engineering, vol. 29, no. 8, Article ID 4017077, 2017.

[25] M. Ahmad, H. M. Faisal, U. A. Mannan, and R. A. Tarefder, "Effects of pore structure on oxidative aging and related mechanical properties of asphalt concrete," Construction and Building Materials, vol. 151, pp. 636-641, 2017.

[26] X. Zhao, S. Wang, Q. Wang, and H. Yao, "Rheological and structural evolution of SBS modified asphalts under natural weathering," Fuel, vol. 184, pp. 242-247, 2016.

[27] S. Xu, J. Yu, C. Zhang, and Y. Sun, "Effect of ultraviolet aging on rheological properties of organic intercalated layered double hydroxides modified asphalt," Construction and Building Materials, vol. 75, pp. 421-428, 2015.

[28] E. Hagos, A. Molenaar, M. Van de Ven, and J. Voskuilen, "Durability related investigation into porous asphalt," in Proceedings of the International Conference on Advanced Characterisation of Pavement and Soil Engineering Materials, pp. 20-22, Athens, Greece, 2007.

[29] C. Hu, J. Youtcheff, D. Wang, X. Zhang, E. Kutay, and S. Thyagarajan, "Characterization of asphalt mixture homogeneity based on X-ray computed tomography," Journal of Testing and Evaluation, vol. 40, no. 7, pp. 1-7, 2012.

[30] H. Wang, Z. Huang, L. Li, Z. You, and Y. Chen, "Threedimensional modeling and simulation of asphalt concrete mixtures based on X-ray CT microstructure images," Journal of Traffic and Transportation Engineering, vol. 1, no. 1, pp. 55-61, 2014.

[31] E. Masad, V. K. Jandhyala, N. Dasgupta, N. Somadevan, and N. Shashidhar, "Characterization of air void distribution in asphalt mixes using X-ray computed tomography," Journal of Materials in Civil Engineering, vol. 14, no. 2, pp. 122-129, 2002.

[32] E. Masad, B. Muhunthan, N. Shashidhar, and T. Harman, "Internal structure characterization of asphalt concrete using image analysis," Journal of Computing in Civil Engineering, vol. 13, no. 2, pp. 88-95, 1999.
[33] L. Gao, F. Ni, H. Luo, and S. Charmot, "Characterization of air voids in cold in-place recycling mixtures using X-ray computed tomography," Construction and Building Materials, vol. 84, pp. 429-436, 2015.

[34] E. Masad, L. Tashman, D. Little, and H. Zbib, "Viscoplastic modeling of asphalt mixes with the effects of anisotropy, damage and aggregate characteristics," Mechanics of Materials, vol. 37, no. 12, pp. 1242-1256, 2005.

[35] A. R. Coenen, M. E. Kutay, N. R. Sefidmazgi, and H. U. Bahia, "Aggregate structure characterisation of asphalt mixtures using two-dimensional image analysis," Road Materials and Pavement Design, vol. 13, no. 3, pp. 433-454, 2012.

[36] L. Bruno, G. Parla, and C. Celauro, "Image analysis for detecting aggregate gradation in asphalt mixture from planar images," Construction and Building Materials, vol. 28, no. 1, pp. 21-30, 2012.

[37] N. Otsu, "A threshold selection method from gray-level histograms," IEEE Transactions on Systems, Man, and Cybernetics, vol. 9, no. 1, pp. 62-66, 1979.

[38] L. Vincent, Morphological Area Openings and Closings for Grey-Scale Images, Shape in Picture, Springer, Berlin, Germany, 1994.

[39] K. N. Ngan, T. Meier, and D. Chai, Advanced Video Coding: Principles and Techniques: The Content-Based Approach, Elsevier, Amsterdam, Netherland, 1999.

[40] A. E. Alvarez, A. E. Martin, and C. Estakhri, "Effects of densification on permeable friction course mixtures," Journal of Testing and Evaluation, vol. 37, no. 1, pp. 11-20, 2009.

[41] F. Montes and L. Haselbach, "Measuring hydraulic conductivity in pervious concrete," Environmental Engineering Science, vol. 23, no. 6, pp. 960-969, 2006.

[42] H. Peng, J. Yin, and W. Song, "Mechanical and hydraulic behaviors of eco-friendly pervious concrete incorporating fly ash and blast furnace slag," Applied Sciences, vol. 8, no. 6, p. 859, 2018.

[43] R. Zhong, M. Xu, R. Vieira Netto, and K. Wille, "Influence of pore tortuosity on hydraulic conductivity of pervious concrete: characterization and modeling," Construction and Building Materials, vol. 125, pp. 1158-1168, 2016. 